\title{
Improving the efficiency of anaerobic disposal of organic waste
}

\author{
Vladimir Shcherbakov ${ }^{1}$, Valentina Pomogaeva ${ }^{1}$, Tatyana Shukina ${ }^{1}$, Konstantin Chizhik $^{2 *}$, and \\ Victor Bazhenov ${ }^{3}$ \\ ${ }^{1}$ Voronezh State Technical University, Moscow Avenue, 14, Voronezh, 394026, Russia \\ ${ }^{2}$ Moscow State University of Civil Engineering, Yaroslavskoe shosse, 26, Moscow, 129337, Russia \\ ${ }^{3}$ Closed Joint Stock Company "Water and Waste Water", 1, Polkovaya Str, Moscow, 127018, Russia
}

\begin{abstract}
Experimental studies on the decontamination and stabilization of sludge sites sediment with calcium oxide treated with disinfectant. The results of the research discovered that the sewage sludge of Voronezh City is safe and can be used as organic fertilizer for growing agricultural plants. Determination of the content of macro-elements of mineral nutrition in the soil and the reaction of its environment showed that the application of organic fertilizers in the form of sludge increases the amount of nitrate nitrogen, exchangeable potassium, mobile phosphorus in the soil compared to the non-fertilized sample. Contemporaneously, the mass fraction of impurities of toxic elements in the soil decreases when the sewage sludge is used as an organic-lime fertilizer.
\end{abstract}

\section{Introduction}

Water management and municipal enterprises in Russia store more than a hundred million tons of organic sediments, not considering waste from livestock complexes. Sewage sludge is formed in the process of physico-chemical and biological treatment at domestic and industrial wastewater treatment plants. In most cases, the sewage sludge is fed to the silt sites for dewatering. Currently, most of the silt sites are overflown and are often located in the residential territory of cities.

The volume and characteristics of sediments generated at sewage treatment plants can be categorized according to the following characteristics [1-5]:

- The amount of waste on grates with openings of $16 \mathrm{~mm}$ is $81 /$ person per year - at a humidity of $80 \%$ and a volume weight of $750 \mathrm{~kg} / \mathrm{m}^{3}$;

- Volume of sand retained by sand traps is $0.02-0.03 \mathrm{l} /$ person/day, volume weight- 1.5 $\mathrm{t} / \mathrm{m}^{3}$, humidity- $60 \%$;

- Volume of floating sediments retained by fat traps or primary sedimentation tanks is 2 $1 /$ person per year at a humidity of $60 \%$ and a volume mass of $0.6 \mathrm{t} / \mathrm{m}^{3}$;

- Suspended pollution is retained by primary sedimentation tanks. The mechanical composition of sediments from primary sedimentation tanks is highly heterogeneous.

* Corresponding author: irkyt-44@yandex.ru 
The size of individual particles ranges from $10 \mathrm{~mm}$ or more to particles of colloidal and molecular dispersion;

- The active sludge retained by the secondary settling tanks is a thin suspension and consists of $98 \%$ by weight of particles smaller than $1 \mathrm{~mm}$. The humidity of activated sludge discharged from secondary settling tanks after the aeration tank is $99.2-99.6 \%$, and $96-96.5 \%$ after biofilters;

- Cake - the sediment after mechanical dewatering or dried on silt platforms.

- Sediments contain toxic and carcinogenic substances, synthetic surfactants, and heavy metal salts. The content of these substances is determined by the presence of industrial wastewater impurities in domestic wastewater, bacteriological contamination (protozoa, bacteria, algae), parasites (helminth eggs). In the active sludge, in addition to aerobic bacteria, there are mold and yeast fungi, protozoa, and pathogenic bacteria. All this is the reason for the sanitary and epidemiological danger of sediments, which requires mandatory disinfection.

Since organic sediments belong to the fourth or fifth hazard class depending on the composition, the problem of their disposal is relevant. Environmental, economic and social parameters are important aspects of recycling [6].

Currently, the disposal of sediment is to bury it in landfills. Since urban wastewater sludge is a valuable organomineral product, its application for the cultivation of agricultural products is a promising tendency. The solid phase of sediments consists by more than $50 \%$ of organic substances, as well as nitrogen, phosphorus and potassium complexes. Organic and mineral substances increase the yield of cultivated plants when they are applied into the soil [7-10].

The use of sediments is restrained due to the risk of detection presence of pathogenic microorganisms and heavy metals in them, which is unacceptable when applied to the soil. According to sanitary and hygienic indicators, the safety of sewage sludge is determined by the presence of pathogenic microorganisms and helminth eggs [11,12]. Decontamination of sewage sludge can be carried out by adding lime, thiazone, ammonia, formaldehyde, urea and other chemicals. In addition to the decontamination effect, such a sediment can be applied into the soil as fertilizer, since the nutrients remain and positively affect the productivity of plants $[13,14]$. The residual content of thiazone formaldehyde and ammonia in the sediments prevents the development of microorganisms and maintains the stability of the sediments. However, these substances are toxic, requiring careful application and handling [15-18]. To prevent contamination of the soil and groundwater with nitrogen, it is necessary to consider the degree of its assimilation by plants, the proportion of it contained in the soil, and, depending on this, set the dose of applying the decontaminated sediment to the soil. The dose of sediments treated with other substances should also be determined taking into account their effect. $[11,19,20]$.

\section{Materials and methods}

The amount of sediment added to the soil can be found by the formula below [11]:

$$
D_{h m}=\frac{(0.8 \cdot M P C-A) \cdot 3000}{C_{h m}}
$$

where $D_{h m}$ is the allowable rate of sediment, $\mathrm{t} / \mathrm{ha}$ of dry matter;

$M P C \quad$ - maximum permissible concentration of heavy metal in the soil, $\mathrm{mg} / \mathrm{kg}$;

$A \quad$ - actual content of heavy metal in the soil, $\mathrm{mg} / \mathrm{kg}$;

$C_{h m} \quad$ - heavy metal content in the sediment, $\mathrm{mg} / \mathrm{kg}$ of dry matter; 

- weight of the arable soil layer in terms of dry matter, $\mathrm{t} / \mathrm{ha}$.

The content of heavy metals in the sewage sludge depends on the enterprises that discharge water to the treatment facilities. Such indicators will differ for each city. The MPC value of heavy metals in wastewater sludge is strictly regulated. Table 1 shows the MPC values for different countries and Russia according to regulatory data $[11,12,20]$.

Table 1. MPC value of heavy metals in wastewater sludge

\begin{tabular}{|c|c|c|c|c|c|c|c|c|c|}
\hline \multirow[b]{2}{*}{$\mathrm{TM}$} & \multicolumn{9}{|c|}{ MPC of HM in sediment ( $\mathrm{mg} / \mathrm{kg}$ of dry matter) } \\
\hline & 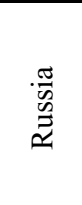 & 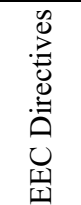 & $\begin{array}{l}\vec{E} \\
\stackrel{\vec{E}}{\Xi}\end{array}$ & 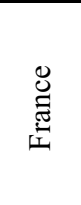 & $\begin{array}{l}\text { चี } \\
\text { D. } \\
\dot{3} \\
\text { un }\end{array}$ & $\begin{array}{l}\vec{Z} \\
\text { 咅 } \\
\bar{I}\end{array}$ & 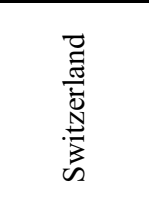 & 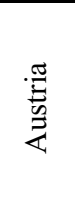 & 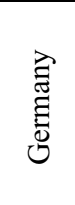 \\
\hline As & 20 & - & - & - & - & - & - & - & - \\
\hline $\mathrm{Co}$ & - & - & 100 & 200 & - & - & $80-150$ & 100 & - \\
\hline $\mathrm{Cr}$ & 1200 & 750 & 1000 & 200 & 1000 & 500 & $900-1500$ & 500 & 1200 \\
\hline $\mathrm{Cu}$ & 1500 & 1000 & 3000 & 1500 & 3000 & 500 & $900-1500$ & 500 & 1200 \\
\hline $\mathrm{Cd}$ & 30 & 20 & 30 & 15 & 15 & 10 & $25-40$ & 10 & 20 \\
\hline $\mathrm{Ni}$ & 400 & 300 & 500 & - & - & 100 & $150-300$ & 200 & 200 \\
\hline $\mathrm{Hg}$ & 15 & 16 & 25 & 8 & 8 & 10 & $8-15$ & 10 & 25 \\
\hline $\mathrm{Zn}$ & 4000 & 2500 & 5000 & 3000 & 10000 & - & $2500-4000$ & 2000 & 3000 \\
\hline $\mathrm{Mn}$ & 2000 & - & 3000 & 500 & - & - & - & - & - \\
\hline $\mathrm{Pb}$ & 1000 & 750 & 1200 & 300 & 300 & 500 & $900-1500$ & 500 & 1200 \\
\hline
\end{tabular}

Analyzing this table, we can conclude that the Russian standards correspond to generally accepted international ones. In terms of arsenic content, they are higher than in the above countries.

Experimental studies on improving the efficiency of anaerobic stabilization of organic waste generated at a sewage treatment plant were carried out using lime in a decanter centrifuge. The general view of the installation is shown in Fig.1. The installation consists of a lime feed hopper (pos. 2), a screw mixer of sludge with lime (pos. 3). The sediment was previously dewatered on filter presses. Quicklime from the silo goes through the lime feed screw to the screw mixer, where the lime is mixed and dosed with the sediment. The discharge of the treated sludge is carried out in an automated mode.

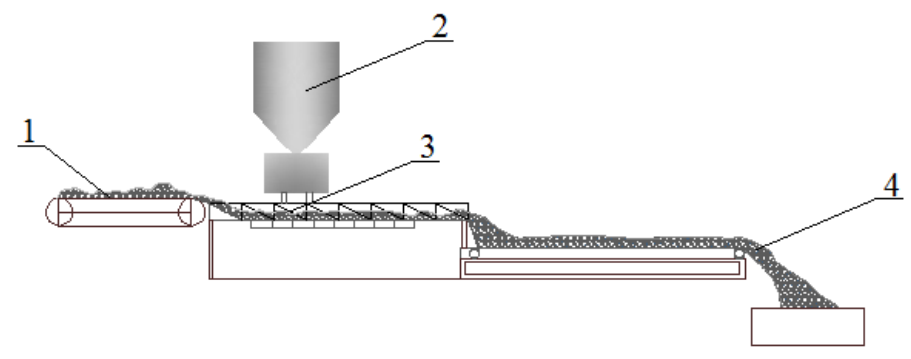

Fig. 1. Scheme of treatment of dehydrated sludge:

1-dehydrated sludge; 2-lime feed; 3-screw mixer of sludge with lime; 4-discharge of treated sludge.

Studies on the use of a decontaminating agent were carried out at the wastewater treatment facilities of Voronezh City. The treatment of organic waste was carried out with calcium oxide treated with an ovicidal preparation. The decontaminating reagent is SE-1 (ROSUN) - white or grey powder with a moisture content of $0.5 \%$, a volume density of at least 0.9 
$\mathrm{g} / \mathrm{cm}^{3}$, and a water solubility of up to $20 \mathrm{~g} / \mathrm{l}$. It is a strong oxidizing agent that provides, in addition to affecting pollutants, a decontaminating effect. The composition of the reagent includes the following substances:

- $\quad$ Potassium monopersulfate (double salt up to $18-24 \%$ );

- $\quad$ Sodium chloride (1-5\%);

- $\quad$ Active oxygen (7-9\%).

There is a safety passport for the reagent, which includes all 17 items required for the corresponding document in the Russian Federation. According to the safety data sheet, the product undergoes biological oxidation and does not biologically accumulate. The decontaminating effect of the reagent is also provided by its pronounced oxidizing ability. The mechanism of the bactericidal effect is in blocking the transfer of ribonucleic acid and destroying the genetic system. When dissolved in water, active oxygen, hydroxyl free radical, hydrogen peroxide, and hypochlorous acid are formed. All components act simultaneously on organic substances of technogenic and natural origin and inorganic substances with variable valence.

With the application of a decontaminating reagent in an amount not exceeding $2 \%$ by weight, it can be used for decontamination, stabilization and deodorization of both urban treatment facilities and local treatment facilities of industrial enterprises sewage sludge in combination with other treatment technologies.

With the application of a decontaminating reagent in an amount not exceeding $1.5 \%$ by weight, in addition to previously listed sediments, it can be used for decontamination, stabilization and deodorization of the effluents of livestock and poultry complexes. The main parameters of the applied reagent should contain at least $80 \%$ of the active $\mathrm{CaO}$, the fractional composition of the grains should not be more than 200 microns, the bulk density should not be less than $700 \mathrm{~kg} / \mathrm{m}^{3}$. If these parameters are reached, the reaction temperature with water is $70-85^{\circ} \mathrm{C}$, with a reaction time of $3-15$ minutes.

The experimental studies on determination of the toxic elements content in the treated sediment were conducted at the Left-bank wastewater treatment facilities in Voronezh (LOS, LLC).

\section{Results and discussion}

During the sewage sludge decontamination experiments the problems with the reaction of lime arised. Absolutely dehydrated sediment did not fully reacted with lime, thus, the expected decontamination effect was not achieved. Therefore, the required moistness of the sediment was set. Experiments were conducted with raw sludge and a raw sludge and excess activated sludge mixture. Sediment, excess activated sludge, and $\mathrm{CaO}$ were mixed in different proportions in order to get the generalized studies results. Various samples data are shown in the following table.

Table 2. Samples of sludge from wastewater treatment plants

\begin{tabular}{|c|c|c|c|}
\hline \multirow{2}{*}{ Sample } & \multicolumn{3}{|c|}{ Content in the sample, \% } \\
\cline { 2 - 4 } & raw sludge & excess active sludge & $\mathrm{CaO}$ \\
\hline №1 & 100 & - & 5 \\
\hline №2 & 100 & - & 7 \\
\hline №3 & 30 & 70 & 3 \\
\hline №4 & 10 & 90 & 5 \\
\hline №5 & 30 & 70 & 5 \\
\hline
\end{tabular}


The most optimal option for applying treated sediment to the soil is sample No. 5. The amount of sediment applied was determined by the formula (1), taking into account the heavy metals content in the soil and sediment

For dewatered sludge (30\% crude sludge, $70 \%$ excess activated sludge) of treatment facilities, the application dose calculated for $60 \mathrm{~kg}$ of active substance per ha in terms of nitrogen content was $4.45 \mathrm{t} / \mathrm{ha}$, while for treated with $\mathrm{CaO}$ with $5 \%$ of decontaminating additive it was $3.78 \mathrm{t} / \mathrm{ha}$. The sediment was applied under the main tillage.

Studies conducted at treatment facilities show that the mass fraction of toxic elements in the sludge after treatment is not significant. The determination of heavy metals in samples was conducted in the State Center of Agrochemical Service "Voronezhsky". The mass fraction of heavy metal impurities in the dewatered sludge treated with $\mathrm{CaO}$ and the normative content are presented in Table 3.

Table 3. Research parameters of sewage sludge

\begin{tabular}{|l|c|c|c|}
\hline \multicolumn{1}{|c|}{ Parameter } & $\begin{array}{c}\text { Regulatory } \\
\text { requirements }\end{array}$ & Sludge & $\begin{array}{c}\text { CaO } \\
\text { treated } \\
\text { Sludge }\end{array}$ \\
\hline \multicolumn{1}{|c|}{$\mathbf{1}$} & $\mathbf{2}$ & $\mathbf{3}$ & $\mathbf{4}$ \\
\hline $\mathbf{H}_{\mathbf{2}} \mathbf{O}, \%$ & $<<82$ & 36,4 & 63,6 \\
\hline $\mathbf{p H}$ & $5,5-8,5$ & 6,4 & 12,2 \\
\hline Organic fraction in dry matter, \% & $40-60$ & 72,9 & 66,1 \\
\hline $\mathbf{N i t r o g e n ~ f r a c t i o n , \% ~}$ & $1-3$ & 1,84 & 2,6 \\
\hline $\mathbf{P}_{\mathbf{2}} \mathbf{O}_{\mathbf{5}}, \%$ & $1-4$ & 1,14 & 1,4 \\
\hline $\mathbf{K}_{\mathbf{2}} \mathbf{O}, \%$ & $0,2-0,7$ & 0,1 & 0,13 \\
\hline $\mathbf{H g}, \mathrm{mg} / \mathrm{kg}$ & 15 & 0,45 & 0,41 \\
\hline $\mathbf{C r}, \mathrm{mg} / \mathrm{kg}$ & $<1200$ & 48,3 & 20,7 \\
\hline $\mathbf{P b}, \mathrm{mg} / \mathrm{kg}$ & $<1000$ & 114,9 & 97,1 \\
\hline $\mathbf{N i}, \mathrm{mg} / \mathrm{kg}$ & $<400$ & 27,2 & 20,4 \\
\hline $\mathbf{A s}, \mathrm{mg} / \mathrm{kg}$ & $<20$ & 0,5 & 0,6 \\
\hline $\mathbf{H C H}, \mathrm{mg} / \mathrm{kg}$ & $<0,1$ & $<<0,007$ & $<<0,005$ \\
\hline $\mathbf{D D T}, \mathrm{mg} / \mathrm{kg}$ & $<0,1$ & $<<0,005$ & $<<0,005$ \\
\hline
\end{tabular}

The use of lime-stabilized sediment on agricultural land is constrained by the presence of toxic elements and parasitological indicators in wastewater sediments. However, the carried out experiments and the obtained results of the analysis show that the use of such sediment is safe. As it is shown in Table 3, the mass fraction of heavy metal impurities in the treated sediment is significantly less than the required ones [12].

Accordingly, the resulting sediments can be applied to reclamation fields with a frequency of no more than 2-3 years, in the amount of 5-15 t/ha in terms of dry matter, according to the formula (1).

The concentration of substances necessary to improve soil fertility increases when the sediment is treated with lime $[8-10,16]$. A decrease in the content of heavy metals in the treated sludge compared to the initial concentration in the sewage sludge was revealed.

One of the main factors of influence of the applied treated sediment on soil fertility is the content of macronutrients of mineral nutrition in the soil and the reaction of the soil environment. During the studies, an increase in the content of exchangeable potassium in the soil by $3.5 \mathrm{mg} / 100 \mathrm{~g}$ of absolutely dry soil (or by $18.6 \%$ ) was observed. The increase in the content of mobile phosphorus was different: when applying dehydrated sludge, it increased by $4.5 \mathrm{mg} / 100 \mathrm{~g}$ of absolutely dry soil (or by $7.6 \%$ ), and when applying sludge treated with $\mathrm{CaO}$, it remained almost at the control level. An increase in the content of nitrate nitrogen in the soil with silt sediment was $0.8 \mathrm{mg} / \mathrm{kg}$ of absolutely dry soil (or by 
$11.9 \%$ ), with $\mathrm{CaO}$ it was $1.5 \mathrm{mg} / \mathrm{kg}$ of absolutely dry soil (or by $22.4 \%$ ). The determination was carried out during the growth of five real rapeseed leaves.

Application of sewage sludge treated with $\mathrm{CaO}$ changes the reaction of the soil environment to increasing the alkalinity of the soil solution by $0.11 \mathrm{pH}$ units compared to the control version, which is significantly less than accepted in the practice of design and operation $[15,16,19]$. Thus, the use of such wastewater sludge will be more effective on soils with an acidic reaction of the medium.

\section{Conclusions}

1. Voronezh City wastewater sludge treated with $\mathrm{CaO}$ is safe and refers to clean soils in accordance with regulatory requirements by its microbiological parameters,.

2. In accordance with the regulatory requirements, the sewage sludge of the Voronezh silt sites is safe in terms of the content of toxic elements which is significantly less than the regulatory ones and can be used as organic fertilizer in reclamation.

3. As a result of the use of silt sludge treated with $\mathrm{CaO}$ and SE-1 decontaminating agent, pathogenic microflora, viable helminth eggs, cysts of pathogenic intestinal protozoa, enterococci and other dangerous biological agents are destroyed.

4. Dewatered sludge treated with $\mathrm{CaO}$ and SE-1 decontamination agent can be used in industrial floriculture, forestry and for biological reclamation of disturbed lands and landfills. The application of such sediment increases the fertility of the soil, by increasing the content of nitrogen, phosphorus and potassium in the soil and leads to an increase in the yield of winter rapeseed by $20.1 \%$. As organic fertilizer the silt sludge does not affect the quality of the grown plants. All indicators are within the maximum permissible concentrations (MPC) or significantly lower.

\section{References}

1. I.S. Turovsky, Sewage sludge. Dehydration and disinfection, 376 (2018)

2. Yu.V. Voronov, S.V. Yakovlev, Wastewater and wastewater treatment, 702 (2006)

3. Degremont, Technical guide to water treatment. New book, 1 (2007)

4. A. Z. Evilevich, M.A. Evilevich, Utilization of waste water sediments, 247 (1988)

5. E.P. Doskina, A.V. Moskvicheva, E.V. Moskvicheva, A.A. Gerashchenko, Treatment and disposal of urban wastewater sediments, 184 (2018)

6. S.A. Dovgan, Ecological, technological and economic aspects of sewage sludge use. Ecology and Industry of Russia 5, 25-30 (2012)

7. V.I. Sherbakov, K.I. Chizhik, V.V. Pomogaeva, O.Y. Tararykov, The study of the use of "Dezolak" for disinfection and deodorization of sewage sludge Conference Series: Materials Science and Engineering. (2020)

8. V.I. Shcherbakov, V.V. Pomogaeva, K.I. Chizhik, E. Koroleva, Biomass resource of domestic sewage sludge. Advances in Intelligent Systems and Computing. 983, 361372 (2019)

9. V.I. Shcherbakov, V.V. Pomogaeva, The use of sewage sludge for growing crops. Yakovlevskie readings collection of reports of the XIII International Scientific and Technical Conference dedicated to the memory of academician of the RAS S.V. Yakovleva. National Research Moscow State University of Civil Engineering. 155-160 (2018)

10. V.I. Shcherbakov, V.V. Pomogaeva, Studies on the use of sludge for soil application 266-270 (2019). 
11. Hygienic requirements for the use of wastewater and their sludge for irrigation and fertilization, 54 (1997)

12. Conservation of nature. Soil. Requirements for the properties of sewage sludge when used as fertilizers, 8 (2008)

13. I.V. Khutoryanina, L.L. Dimidova, E.P. Khromenkova, T.I. Tverdokhlebova, Methods and means for disinvasion of environmental objects. 3 (300), 54-56 (2018).

14. V.A. Archipenko, A.M. Nazarov, L.Kh Araslanova, Purification of waste sediments from heavy metals using sorbents, 70-74 (2020)

15. T.A. Vasilenko, A.Kh. Mohammed, The use of sludge from mechanical and biological treatment of domestic and industrial wastewater as fertilizer, 6, 211-219 (2016).

16. E.E. Vasilevich, R.N. Rudenko, New approaches to the disposal of sewage sludge, 5355 (2016).

17. A.V. Ignatenko, Decontamination of sewage sludge and methods of its control, 4, 210213 (2016).

18. D.D. Kalimullina, I.Z. Bagautdinov, Features of reagent stabilization of sewage sludge, 5/ ISSN 2410-6070. (2016)

19. D.A. Danilovich, Modern methods of disinfection of sewage sludge, NDT, 6, 50-54 (2018).

20. Sanitary and epidemiological requirements to soil quality: Sanitary and epidemiological rules and regulations, 16 (2004) 